\title{
Multidrug-Resistant Tuberculosis in an Adult with Cystic Fibrosis
}

\author{
K. Manika P. Giouleka K. Zarogoulidis I. Kioumis
}

Adult Cystic Fibrosis Unit, Pulmonary Department, Aristotle University of Thessaloniki, 'G. Papanikolaou' Hospital, Thessaloniki, Greece

\section{Established Facts}

- Nontuberculous mycobacteria have been isolated from patients with cystic fibrosis worldwide.

- Mycobacterium tuberculosis infection in patients with cystic fibrosis is rare.

\section{Novel Insights}

- The possibility of tuberculosis should not be excluded in patients with cystic fibrosis.

- Resistance profiles of colonizing bacteria and M. tuberculosis should lead to a considered formulation of an effective antituberculosis regimen.

\section{Key Words}

Cystic fibrosis - Tuberculosis • Multidrug resistance

\begin{abstract}
Mycobacterium tuberculosis infection in patients with cystic fibrosis (CF) is rare. We report a 22-year-old CF patient with high fever, dyspnea and weight loss that progressively worsened over 2 weeks before admission. The patient suffered from liver cirrhosis, was colonized with Pseudomonas aeruginosa and had been repeatedly hospitalized for pulmonary infections. The patient was treated initially as for an exacerbation of $P$. aeruginosa infection, but tuberculosis (TBC) was suspected due to lack of improvement. A CT of the chest re-
\end{abstract}

vealed enlarged bilateral cavities in the upper and middle lobes. A tuberculin skin test was positive, and $M$. tuberculosis nucleic acid was isolated from sputum samples. After receiving first-line anti-TBC drugs for 1 month, the patient's condition continued to worsen so molecular drug susceptibility testing was performed. Multidrug-resistant TBC was discovered, leading to a change in regimen. The patient was treated with ethionamide, moxifloxacin, linezolid, amikacin, imipenem/cilastatin and rifabutin and showed a remarkable clinical improvement. Although nontuberculous mycobacteria are more common in CF, the possibility of TBC should not be ignored. In that setting, early suspicion of infection due to resistant $M$. tuberculosis can be life saving.

Copyright @ 2012 S. Karger AG, Basel

\section{KARGER}

Fax +41613061234

E-Mail karger@karger.com

www.karger.com
(C) 2012 S. Karger AG, Basel

$0025-7931 / 13 / 0854-0350 \$ 38.00 / 0$

Accessible online at: www.karger.com/res
Asst. Prof. Ioannis Kioumis

Pulmonary Department

Aristotle University of Thessaloniki, 'G. Papanikolaou' Hospital

GR-57010 Exohi, Thessaloniki (Greece)

Tel. +30231330 7974, E-Mail ikioum@yahoo.gr 


\section{Introduction}

The association between infection from nontuberculous mycobacteria and cystic fibrosis (CF) is well established [1-5]. In France, the prevalence was reported to be $6.6 \%$ [1], whereas in the USA, nontuberculous mycobacteria were cultured from $13 \%$ of $\mathrm{CF}$ patients more than 10 years old [2]. On the other hand, tuberculosis (TBC) has only rarely been described in patients with CF [6-9]. Our case report concerns a $\mathrm{CF}$ patient with respiratory failure and cirrhosis who developed multidrug-resistant (MDR) pulmonary TBC.

\section{Case Report}

A 22-year-old female CF patient (homozygous $\Delta$ F508 mutation) who had been followed up in the adult CF unit of our department for several years presented with a history of high fever over the previous 2 weeks and episodes of low-grade fever during the previous 3 months. The patient was HIV negative, suffered from liver cirrhosis, was permanently colonized with Pseudomonas aeruginosa and had been repeatedly hospitalized for pulmonary infections during the previous 2 years. She did not report any drug abuse and was not diabetic.

On admission, her overall clinical condition, chest X-ray and spirometric findings had deteriorated compared to her previous status, and she presented with hypoxemia (oxygen tension: $57 \mathrm{~mm}$ $\mathrm{Hg}$; oxygen saturation: $89 \%$ ). Results of pulmonary function tests were as follows: forced expiratory volume in $1 \mathrm{~s}\left(\mathrm{FEV}_{1}\right) 1.150$ liters (37.8\%), forced vital capacity (FVC) 1.890 liters (54\%) and $\mathrm{FEV}_{1} /$ FVC $60 \%$. Blood tests were normal except for elevated C-reactive protein. Extended bilateral infiltrations along with fibrosis and an enlarged cystic space of the right upper lobe were observed on chest X-ray (fig. 1).

Due to her known colonization with $P$. aeruginosa, the patient was initially treated with intravenous tobramycin and ciprofloxacin and then with intravenous colimicin. However, as she continued to deteriorate, a chest CT scan was performed showing mul-

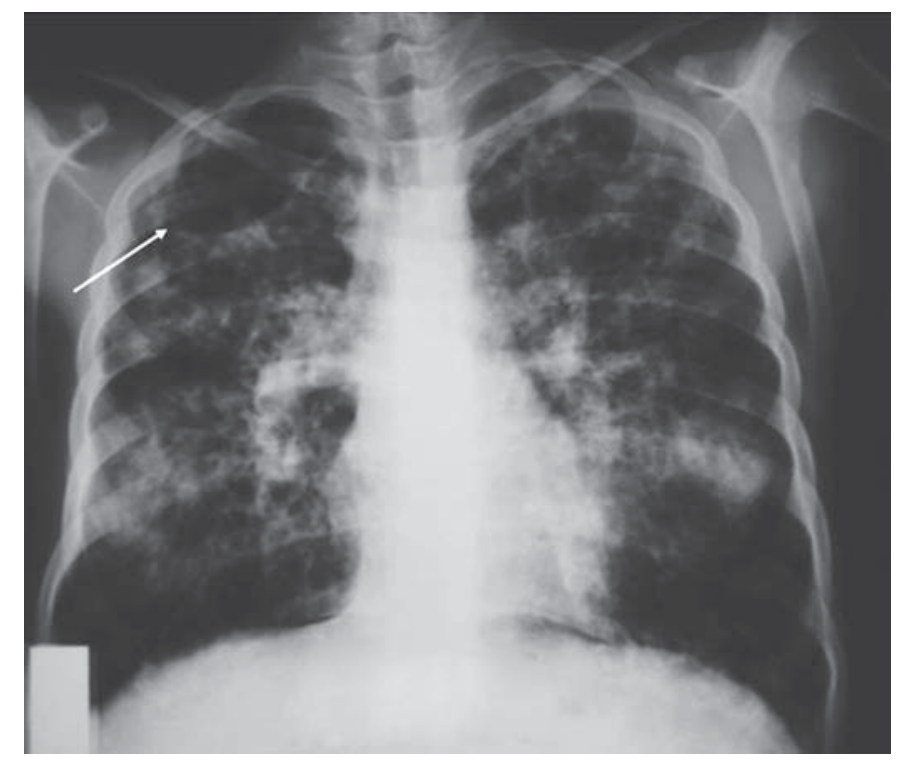

Fig. 1. Chest X-ray on admission showing bilateral infiltrations, fibrosis and an enlarged cystic space in the right upper lobe (arrow).
Fig. 2. a, b CT scans 2 years before the diagnosis of TBC. $\mathbf{c}, \mathbf{d}$ CT scans at the time of diagnosis showing multiple cavities and bronchiectasis, especially in the upper and middle lobes.
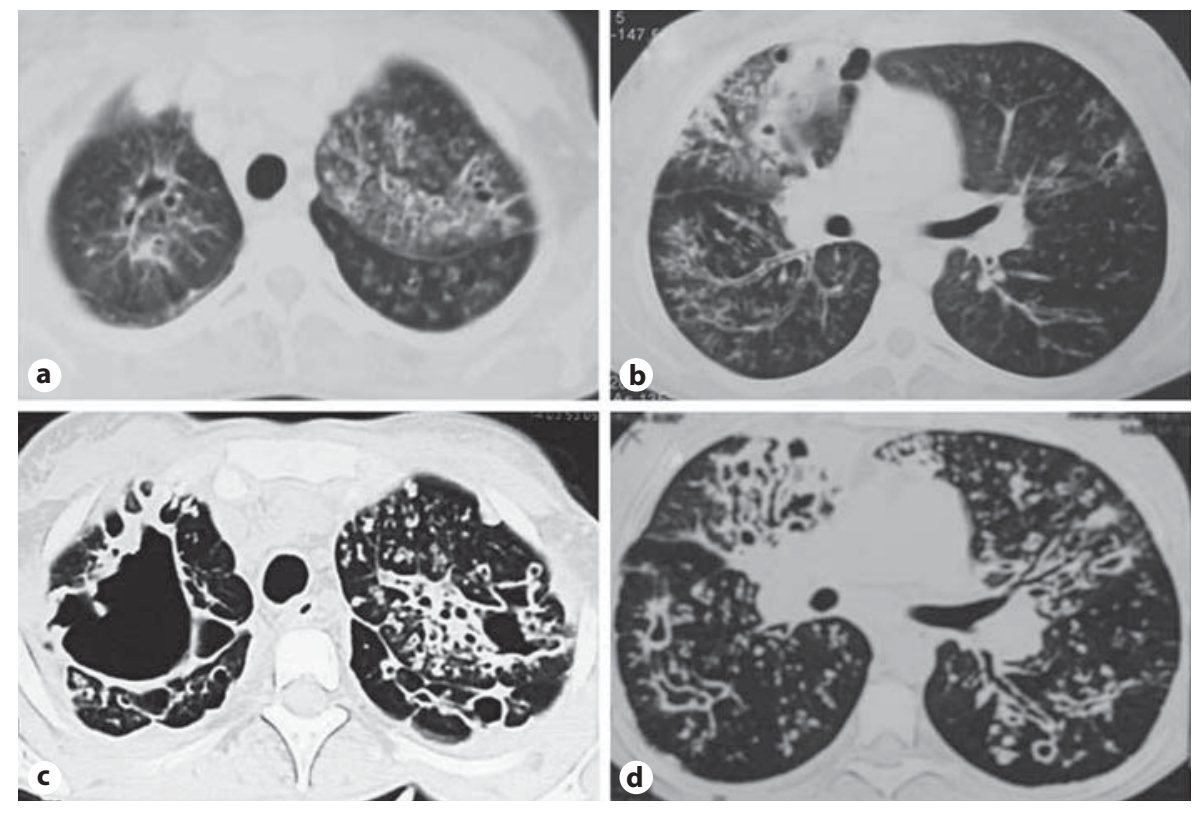
tiple cavities and bronchiectasis especially in the upper and middle lobes (fig. 2). Mycobacterial infection was strongly suspected. The tuberculin skin test was $10 \mathrm{~mm}$, and a sputum nucleic acid amplification method specific for Mycobacterium tuberculosis was found to be positive [Amplified MTD (Gen-Probe) at $2,120,000$ relative light units]. A second test confirmed these results, so the diagnosis of TBC was verified. The patient had never received previous treatment for $\mathrm{TBC}$, so she was given four firstline drugs (isoniazid, rifampicin, pyrazinamide and ethambutol). Nevertheless, her fever persisted and 1 month later acid-fast bacilli were seen on direct smear for the first time. Cultures were repeatedly reported as contaminated but did not yield mycobacterial colonies. Molecular susceptibility testing conducted in the national reference center for mycobacteria revealed resistance to isoniazid, rifampicin, ethambutol, pyrazinamide, streptomycin and quinolones. Resistance to amikacin, kanamycin and capreomycin was not detected.

Based on the above, the patient received ethionamide $(250 \mathrm{mg}$ 3 times a day, i.e. $18 \mathrm{mg} / \mathrm{kg}$ ), moxifloxacin (400 mg, i.e. $9.5 \mathrm{mg} /$ $\mathrm{kg}$ ), linezolid (600 mg twice a day), amikacin, both intramuscular $(750 \mathrm{mg}$, i.e. $18 \mathrm{mg} / \mathrm{kg}$ ) and inhaled (500 $\mathrm{mg}$ twice a day), imipenem/cilastatin (500 mg $\times 3$ for 2 months) and rifabutin (300 mg). Ten days later, she stabilized and her sputum acid-fast stains became negative. She was discharged after having completed a 2-month course of imipenem/cilastatin, still requiring long-term oxygen treatment but afebrile and having gained $4 \mathrm{~kg}$. One month later, linezolid was stopped because of severe pancytopenia and neurotoxicity, and the patient was given para-aminosalicylic acid (4 g twice a day, i.e. $190 \mathrm{mg} / \mathrm{kg}$ ) and cycloserine $(250 \mathrm{mg}$ twice a day, i.e. $18 \mathrm{mg} / \mathrm{kg}$ ). Linezolid was reintroduced a month later at $600 \mathrm{mg}$ daily. After 3 months, the patient's clinical condition and oxygen tension $\left(68 \mathrm{~mm} \mathrm{Hg}\right.$ ) have improved remarkably, her $\mathrm{FEV}_{1}$ and FVC are essentially unchanged and she is being followed up on an outpatient basis.

\section{Discussion}

$\mathrm{CF}$ is often associated with conditions that predispose to developing TBC, such as malnourishment, diabetes mellitus and corticosteroid treatment. However, reports of TBC in patients with $\mathrm{CF}$ are rare. In an older series of 700 patients, Wood et al. [6] reported only 2 cases of active pulmonary TBC. In two more recent prospective studies, the frequency of TBC was somewhat higher but still low (3 out of 226 patients in the study of Smith et al. [7] and 1 out of 54 patients in the study of Hjelte et al. [8]).

The explanation of the surprisingly infrequent occurrence of TBC in CF is not clearly established, although several investigators have suggested that the $\mathrm{CF}$ genetic defect may confer some degree of protection against TBC [10]. Reduced incidence of TBC has also been reported in parents of CF patients [11]. The exact pathogenetic basis of this association remains elusive; however, several path- ways have been suggested, such as an increased production of mucopolysaccharides which may result in successful isolation of a tuberculous pulmonary focus, a deficiency of essential fatty acids and a diminished arylsulfatase activity [11-13].

In the present report, we describe an interesting case of MDR-TBC in a patient with severe CF initially misdiagnosed as exacerbation of $P$. aeruginosa infection. To our knowledge, our case is the first report of pulmonary TBC in CF treated with second- and third-line antituberculous drugs. Asherova et al. [14] published their experience of two CF patients with infection due to M. tuberculosis resistant to all antibiotics that nonetheless responded favorably to the usual first-line regimen.

As in our case, TBC can be easily missed in patients with CF, both clinically and radiologically, due to the preexisting structural abnormalities in the lung parenchyma $[7,14]$. After the diagnosis of TBC had been established, sensitivity testing could not be conducted conventionally, since $M$. tuberculosis could not be isolated from sputum at that point. The observation that sputum from CF patients seems to have a deleterious effect on LowensteinJensen medium has been previously reported [7]. As Smith et al. [7] mention, this phenomenon may explain at least in part the low frequency of TBC diagnosis in CF, since some cases may not be detected. Therefore, molecular methods are of exceptional value not only because they allow early initiation of second-line treatment but also because they are able to detect mycobacterial DNA in sputum samples contaminated with other microorganisms. The lack of availability of molecular susceptibility testing in our department resulted in a 1-month delay of proper treatment.

The choice of the therapeutic regimen in MDR-TBC is particularly difficult. However, many cases can be treated with a combination of rationally selected antiTBC drugs [15]. The recommended regimen consists of at least four active drugs chosen with a stepwise selection process out of five groups $[16,17]$. Since para-aminosalicylic acid (PAS) and cycloserine were not readily available at the time of diagnosis, two group 5 drugs, linezolid and imipenem/cilastatin, were included in the initial second-line regimen. Linezolid is considered to have good activity against M. tuberculosis; however, its efficacy is limited by the frequent side effects [18].

The acquisition mode of $M$. tuberculosis in our patient is unknown. One could hypothesize that it was the result of in-hospital transmission due to the patient's frequent hospital admissions and the fact that MDR-TBC cases are also followed up (although in a separate section) by our 
department. However, the patient was always hospitalized in isolation conditions, and all appropriate measures were taken in order to minimize the possibility of TBC transmission. The acquisition of TBC from the community may be another possible explanation, although no other family member or closely related individual was diagnosed as having TBC. Contact tracing was performed, and one case of latent TBC infection was identified (the patient's mother).
In conclusion, $M$. tuberculosis and, more importantly, resistant strains must be suspected in the case of a nonresolving or otherwise unexplained pulmonary exacerbation in patients with CF. Resistance profiles of colonizing bacteria and M. tuberculosis should lead to a considered formulation of an effective anti-TBC regimen.

\section{References}

$>1$ Roux AL, Catherinot E, Ripoll F, Soismier N, Macheras E, Ravilly S, Bellis G, Vibet MA, Le Roux E, Lemonnier L, Gutierrez C, Vincent V, Fauroux B, Rottman M, Guillemot D, Gaillard JL, Hermann JL: Multicenter study of prevalence of nontuberculous mycobacteria in patients with cystic fibrosis in France. J Clin Microbiol 2009;47:4124-4128.

-2 Olivier KN, Weber DJ, Wallace RJ Jr, Faiz AR, Lee JH, Zhang Y, Brown-Elliot BA, Handler A, Wilson RW, Schechter MS, Edwards LJ, Chakraborti S, Knowles MR: Nontuberculous mycobacteria. I. Multicenter prevalence study in cystic fibrosis. Am J Respir Crit Care Med 2003;167:828-834.

$\checkmark 3$ Oliver A, Maiz L, Canton R, Escobar H, Baquero F, Gomez-Mampaso E: Nontuberculous mycobacteria in patients with cystic fibrosis. Clin Infect Dis 2001;32:1298-1303.

$\checkmark 4$ Sexton P, Harrison AC: Susceptibility to nontuberculous mycobacterial lung disease. Eur Respir J 2008;31:1322-1333.

$>5$ Koch C, Hoiby N: Diagnosis and treatment of cystic fibrosis. Respiration 2000;67:239247.

6 Wood RE, Boat RF, Doershuk CF: Cystic fibrosis. Am Rev Respir Dis 1976;113:833-878.

7 Smith MJ, Efthimiou J, Hodson ME, Batten JC: Mycobacterial isolations in young adults with cystic fibrosis. Thorax 1984;39:369375 .
-8 Hjelte L, Petrini B, Kallenius G, Strandvik B: Prospective study of mycobacterial infections in patients with cystic fibrosis. Thorax 1990;45:397-400.

$\checkmark 9$ Feigelson J, Delaisi B, Pecau Y, Kerzoncuf A, Anagnostopoulos C, Tournier G: Tuberculous pneumopathy in the course of cystic fibrosis. Arch Pediatr 1997;4:1209-1212.

10 Stiehm ER: Disease versus disease: how one disease may ameliorate another. Pediatrics 2006;117;184-191.

11 Meindl RS: Hypothesis: a selective advantage for cystic fibrosis heterozygotes. Am J Phys Anthropol 1987;74:39-45.

-12 Rogiers V, Vercruysse A, Dab I, Baran D: Abnormal fatty acid pattern of the plasma cholesterol ester fraction in cystic fibrosis patients with and without pancreatic insufficiency. Eur J Pediatr 1983;141:39-42.

13 Tobacman JK: Does deficiency of arylsulfatase $\mathrm{B}$ have a role in cystic fibrosis? Chest 2003;123:2130-2139.

14 Asherova IK, Feigelson J, Vasilyeva LA, Gabitov VJ: Cystic fibrosis complicated by multiresistant tuberculosis. Acta Paediatr 2006; 95:1513-1514.
15 Caminero JA, Sotgiu G, Zumla A, Migliori GB: Best drug treatment for multidrug-resistant and extensively drug-resistant tuberculosis. Lancet Infect Dis 2010;10:621-629.

16 Guidelines for the programmatic management of drug-resistant tuberculosis: emergency update 2008. Geneva, World Health Organization, 2008 (WHO/HTM/ TB/2008.402).

17 Falzon D, Jaramillo E, Schünemann HJ, Arentz M, Bauer M, Bayona J, Blanc L, Caminero JA, Daley CL, Duncombe C, Fitzpatrick C, Gebhard A, Getahun H, Henkens M, Holtz TH, Keravec J, Keshavjee S, Khan AJ, Kulier R, Leimane V, Lienhardt C, Lu C, Mariandyshev A, Migliori GB, Mirzayev F, Mitnick CD, Nunn P, Nwagboniwe G, Oxlade O, Palmero D, Pavlinac P, Quelapio MI, Raviglione MC, Rich ML, Royce S, RüschGerdes S, Salakaia A, Sarin R, Sculier D, Varaine F, Vitoria M, Walson JL, Wares F, Weyer K, White RA, Zignol M: WHO guidelines for the programmatic management of drug-resistant tuberculosis: 2011 update. Eur Respir J 2011;38:516-528.

18 Anger HA, Dworkin F, Sharma S, Munsiff SS, Nilsen DM, Ahuja SD: Linezolid use for treatment of multidrug-resistant and extensively drug-resistant tuberculosis, New York City, 2000-06. J Antimicrob Chemother 2010;65:775-783. 